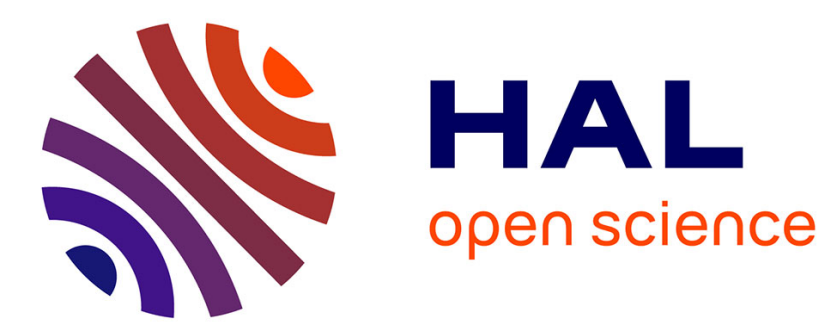

\title{
Recent developments in non-enzymatic catalytic oxidative kinetic resolution of secondary alcohols
}

Helene Pellissier

\section{To cite this version:}

Helene Pellissier. Recent developments in non-enzymatic catalytic oxidative kinetic resolution of secondary alcohols. Tetrahedron, 2018, 74 (27), pp.3459-3468. 10.1016/j.tet.2018.05.015 . hal02091479

\section{HAL Id: hal-02091479 \\ https://hal.science/hal-02091479}

Submitted on 5 Apr 2019

HAL is a multi-disciplinary open access archive for the deposit and dissemination of scientific research documents, whether they are published or not. The documents may come from teaching and research institutions in France or abroad, or from public or private research centers.
L'archive ouverte pluridisciplinaire HAL, est destinée au dépôt et à la diffusion de documents scientifiques de niveau recherche, publiés ou non, émanant des établissements d'enseignement et de recherche français ou étrangers, des laboratoires publics ou privés. 


\section{Recent developments in non-enzymatic catalytic oxidative kinetic resolution of secondary alcohols}

\section{Hélène Pellissier}

Aix Marseille Univ, CNRS, Centrale Marseille, iSm2, Marseille, France

\section{A B S T R A C T}

The goal of this review is to collect the recent developments in non-enzymatic catalytic oxidative kinetic resolutions of secondary alcohols reported since the beginning of 2011. It is divided into four sections, dealing successively with manganese-catalysed oxidative kinetic resolutions of secondary alcohols, palladium-catalysed oxidative kinetic resolutions of secondary alcohols, oxidative kinetic resolutions of secondary alcohols catalysed by other metals and organocatalysed oxidative kinetic resolutions of secondary alcohols.

Keywords:

Catalytic oxidative kinetic resolution

Secondary alcohols

Metal catalysis

Organocatalysis

Asymmetric synthesis

Green chemistry

Chirality

\section{Contents}

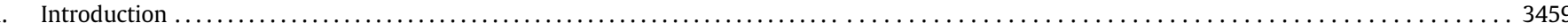

2. Manganese-catalysed oxidative kinetic resolutions of secondary alcohols $\ldots \ldots \ldots \ldots . \ldots 3460$

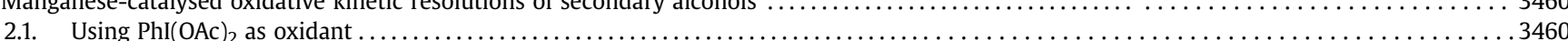

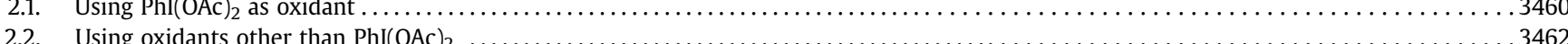

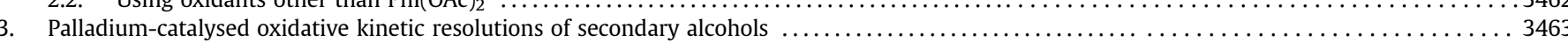

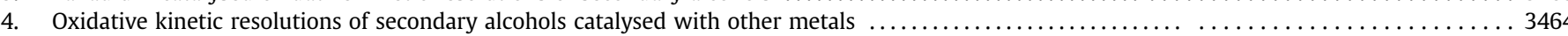

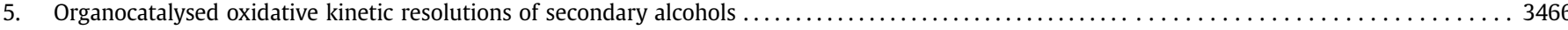

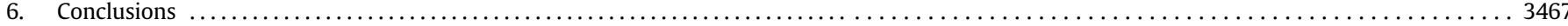

\section{Introduction}

Among a wide number of methodologies for preparing chiral compounds, the kinetic resolution still constitutes the most efficient and practical approach especially in industry. ${ }^{2}$ Along with widely employed kinetic resolutions based on the use of enzymes, transition metal-mediated and more recently developed organocatalysed kinetic resolutions have gained popularity over the last

E-mail address: h.pellissier@univ-amu.fr. few decades due to the progress made in the discovery of novel chiral catalysts. So far, many procedures based on catalytic nonenzymatic kinetic resolution have been developed, providing high enantioselectivities and conversions. The first one was reported by Fajans and Bredig in 1908, dealing with the decarboxylation of camphor-3-carboxylic acid performed with chiral alkaloids. ${ }^{3}$ Then in 1981, a milestone occurred when Sharpless reported the powerful kinetic resolution of allylic alcohols performed with $\mathrm{Ti}(\mathrm{OiPr})_{4} /$ tartrate ligand/tert-butylhydroperoxide as reagent, ${ }^{4}$ which has been widely developed ever since. ${ }^{5}$ Indeed, many reactions based on a kinetic resolution strategy have been achieved 


\begin{tabular}{|llll|}
\hline \multicolumn{2}{|l|}{ Abbreviations } & NBS & N-bromosuccinimide \\
& & NEDA & 1,2-di(1-naphthyl)-1,2-ethanediamine \\
$\mathrm{Ar}$ & aryl & Pent & pentyl \\
$\mathrm{Bn}$ & benzyl & PIFA & phenyl iodonium bis(trifluoroacetate) \\
$\mathrm{Boc}$ & tert-butoxycarbonyl & r.t. & room temperature \\
$\mathrm{Bz}$ & benzoyl & S & selectivity factor \\
$\mathrm{Cbz}$ & benzyloxycarbonyl & salen & N, $N^{\prime}$-ethylenebis(salicylideneiminato) \\
$\mathrm{Cod}$ & cyclooctadiene & TBHP & tert-butyl hydroperoxide \\
$\mathrm{Cy}$ & cyclohexyl & TBS & tert-butyldimethylsilyl \\
ee & enantiomeric excess & TCCA & trichloroisocyanuric acid \\
$\mathrm{MS}$ & molecular sieves & Tf & trifluoromethanesulfonyl \\
$\mathrm{Naph}$ & naphthyl & Tol & tolyl \\
$\mathrm{nbd}$ & norbornadiene & & \\
\end{tabular}

with high efficiency, ${ }^{6}$ such as the oxidative kinetic resolution of alcohols, ${ }^{6,7}$ allowing a practical approach to these chiral pivotal intermediates in asymmetric synthesis, pharmaceutical, agrochemical and fine chemical industries. ${ }^{8}$ This review collects the recent developments in non-enzymatic catalytic oxidative kinetic resolution of secondary alcohols reported since the beginning of 2011 since, to my knowledge, this field was previously reviewed in 2011. ${ }^{6 a}$ It must be noted that the special area of non-enzymatic and not especially oxidative catalytic kinetic resolution of diols was the object of a digest paper reported by Zheng in 2018 including only two references $\geq 2011$, ${ }^{6 \mathrm{~d}}$ and that of asymmetric salen manganesecatalysed oxidative kinetic resolutions of alcohols was reviewed in 2017 by Ahmad et al. containing only eight references $\geq 2011$ among which seven $\leq 2014 .{ }^{9}$ Moreover in 2016, Petersen reported a review on general chiral Brønsted acid-catalysed kinetic resolutions but it included no example of oxidative kinetic resolution of secondary alcohols. ${ }^{10}$ The present review includes oxidative kinetic resolutions of secondary alcohols catalysed by all kinds of chiral catalysts, spanning from chiral complexes derived from all types of metals to chiral organocatalysts. It is divided into four sections according to the nature of the catalysts used to promote these reactions. Indeed, the four sections deal successively with manganese-catalysed reactions, palladium-catalysed reactions, reactions catalysed by other metals and organocatalysed reactions. It must be noted that special kinetic resolutions, such as parallel kinetic resolutions, ${ }^{11}$ stoichiometric kinetic resolutions, ${ }^{12}$ and dynamic kinetic resolutions ${ }^{13}$ are not included in this review.

\section{Manganese-catalysed oxidative kinetic resolutions of secondary alcohols}

\subsection{Using $\mathrm{PhI}(\mathrm{OAc})_{2}$ as oxidant}

Many chiral salen manganese complexes have been successfully applied in the presence of $\mathrm{PhI}(\mathrm{OAc})_{2}$ as oxidant to promote oxidative kinetic resolutions of secondary alcohols, ${ }^{9}$ since the first efficient report by Sun et al., in 2003, allowing enantioselectivities of up to $88 \%$ ee to be achieved by using water as solvent. ${ }^{14}$ Ever since, a number of different types of chiral salen manganese complexes have been successfully investigated by several groups, spanning from monomeric complexes to dimeric, ${ }^{15}$ macrocyclic, polymeric, ${ }^{16}$ and supported ones. ${ }^{17}$ Several of these catalysts are depicted in Scheme 1.

In 2013, Abdi et al. reported the synthesis of novel macrocyclic chiral salen manganese complexes to be evaluated in oxidative kinetic resolutions of racemic secondary alcohols having different steric environment. ${ }^{18}$ The process was performed at $15^{\circ} \mathrm{C}$ with $\mathrm{PhI}(\mathrm{OAc})_{2}$ as oxidant and $\mathrm{KBr}$ as additive in a mixture of

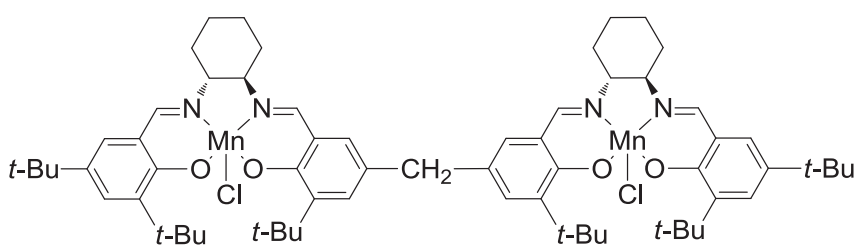

up to $67 \%$ conversion and $97 \%$ ee
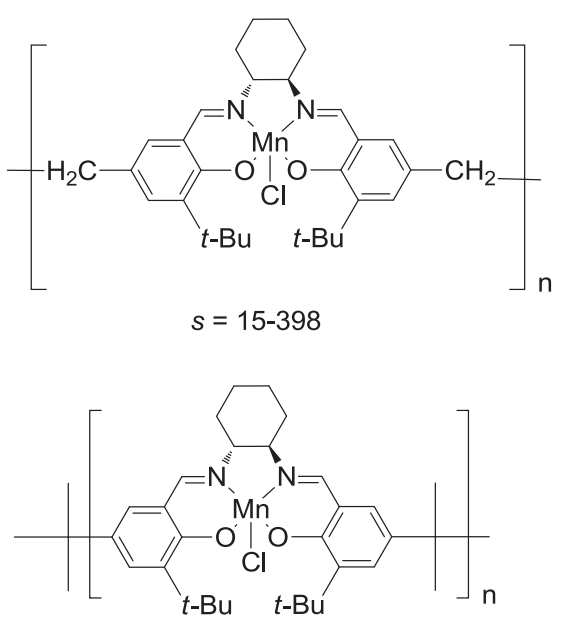

up to $60 \%$ conversion and $>99 \%$ ee

Scheme 1. Recent examples of dimeric and polymeric salen complexes employed in oxidative kinetic resolutions of secondary alcohols by using $\mathrm{PhI}(\mathrm{OAc})_{2}$ as oxidant.

dichloromethane and water as biphasic solvent. It was catalysed by optimal macrocyclic complex 1 at $2 \mathrm{~mol} \%$ of catalyst loading, which provided variable enantioselectivities (7-99\% ee) combined with generally good conversions (53-64\%), as shown in Scheme 2. Notably, the best enantioselectivities (93-99\% ee) were achieved in the oxidative kinetic resolution of aliphatic alcohols while secondary benzylic alcohols provided lower enantioselectivities (7-84\% ee). It must be noted that catalyst 1 was easily recovered through simple precipitation from hexane and could be recycled up to seven times without loss in both enantioselectivity and activity.

Earlier in 2011, Yin and Tan synthesised novel ionic liquidbridged chiral dimeric salen manganese complexes to be investigated in comparable reactions. ${ }^{19}$ Indeed, $N, N$-dialkylimidazolium ionic liquids were used to bridge chiral dimeric salen 


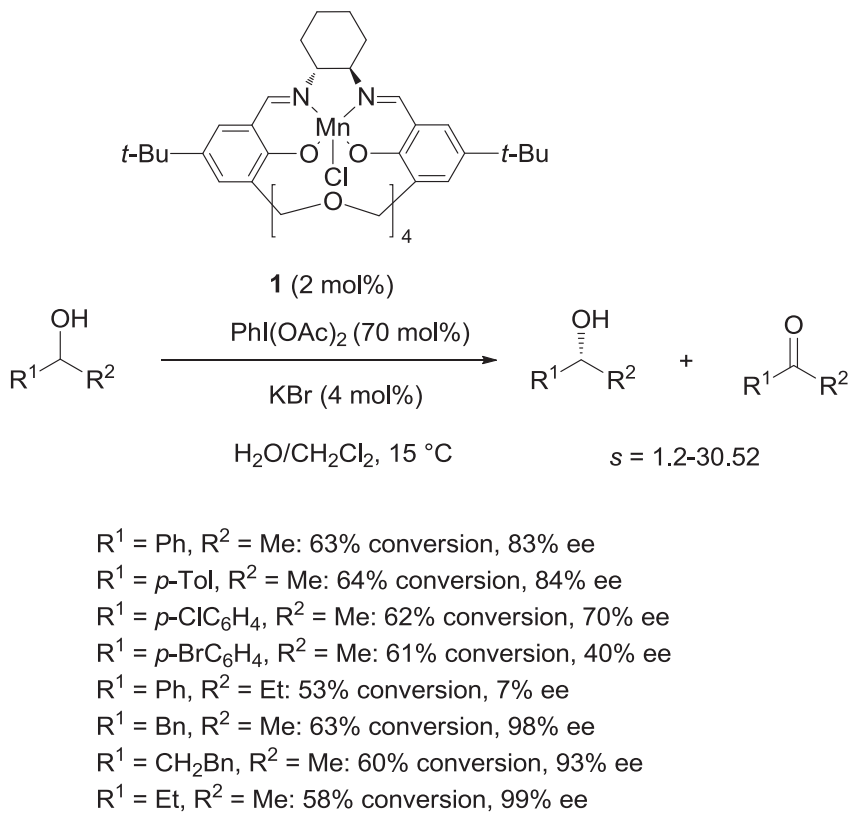

Scheme 2. Oxidative kinetic resolution of secondary alcohols catalysed with a macrocyclic manganese salen complex.

manganese(III) complexes at the C5 position of the salicylaldehyde moieties of the ligand. Among the complexes investigated, catalyst 2 was found optimal at only $1 \mathrm{~mol} \%$ of catalyst loading, providing in the presence of $\mathrm{PhI}(\mathrm{OAc})_{2}$ as oxidant, $\mathrm{KBr}$ as additive and a mixture of dichloromethane and water as solvent, enantioselectivities of up to $>99 \%$ ee. As shown in Scheme 3, the results suggested the importance of the steric hindrance around the hydroxyl group of the substrate either in terms of conversion and enantioselectivity. Indeed, both conversions and enantioselectivities decreased from para-substituted 1-phenylethanols (60-65\% conversion, 92-94\% ee) to ortho-substituted substrates ( $14-32 \%$ conversion, $5-8 \%$ ee). Interestingly, the complex could be efficiently reused up to five times.

In order to perform these reactions in pure water, Yin et al. reported in 2013 the synthesis of a series of novel chiral salen manganese complexes exhibiting a thermoregulated phase-transfer function. ${ }^{20}$ The optimal catalyst prepared through free-radical

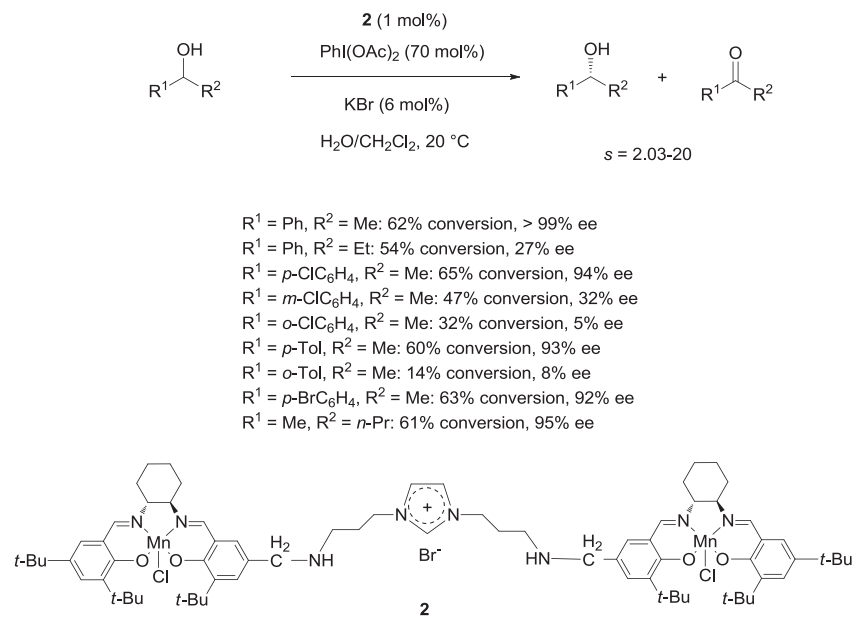

Scheme 3. Oxidative kinetic resolution of secondary alcohols catalysed with an ionic liquid-bridged dimeric salen manganese complex. polymerisation was found to be complex 3 . When $1.5 \mathrm{~mol} \%$ of this complex was applied at $25^{\circ} \mathrm{C}$ in the presence of $\mathrm{PhI}(\mathrm{OAc})_{2}$ as oxidant and $\mathrm{KBr}$ as additive in water as solvent to promote the oxidative kinetic resolution of secondary alcohols, it provided low to excellent enantioselectivities (5-96\% ee) along with low to good conversions (15-63\%), as shown in Scheme 4. Again, both the conversion and enantioselectivity were found highly dependent to the steric hindrance of the substrates. For example, low enantioselectivities (5-8\% ee) were obtained in the reaction of secondary benzylic alcohols bearing a substituent at the ortho-position of the phenyl group $\left(\mathrm{R}^{1}=o-\mathrm{ClC}_{6} \mathrm{H}_{4}\right.$ or $o$-Tol). Moreover, the extension of the $\alpha$-alkyl chain of the substrate (from $\mathrm{R}^{1}=$ Me to $\mathrm{R}^{1}=\mathrm{Et}$ ) resulted in a dramatic decrease in the enantioselectivity (from $96 \%$ ee to $7 \%$ ee). On the other hand, the catalyst was easily recovered and could be recycled for up to four times without loss of both enantioselectivity and activity.

Recently in 2018, Cui et al. designed a supramolecular catalyst constituted by a chiral porous octahedral coordination cage based on a salen manganese catalyst. ${ }^{21}$ Indeed, this chiral cage was built from twelve enantiopure salen manganese-derived dicarboxylic acids as linear linkers and six $Z_{4}$-p-tert-butylsulfonylcalix[4]arene clusters as tetravalent four-connected vertices. The assembly of the metallosalen moieties into the rigid cage structure generated a hydrophobic cavity where the reactants concentrated, and that also stabilised these catalytically active salen manganese moieties against deactivation, thus leading to enhanced catalytic activity and enantioselectivity. The application of this supramolecular catalyst at $1 \mathrm{~mol} \%$ of catalyst loading to the oxidative kinetic resolution of secondary alcohols performed at $0{ }^{\circ} \mathrm{C}$ with $\mathrm{PhI}(\mathrm{OAc})_{2}$ as oxidant, tetraethylammonium bromide as additive in a mixture of dichloromethane and water as solvent provided generally high enantioselectivities of up to $99 \%$ ee along with good conversions (54-62\%). On the other hand, chiral salen manganese complexes immobilised on solid supports have also been successfully applied to promote these reactions with the advantages of better handling and recycling properties compared to their homogeneous counterparts. As a recent example, Sun et al. reported in 2016 the synthesis of a novel mesoporous helica silica immobilised salen

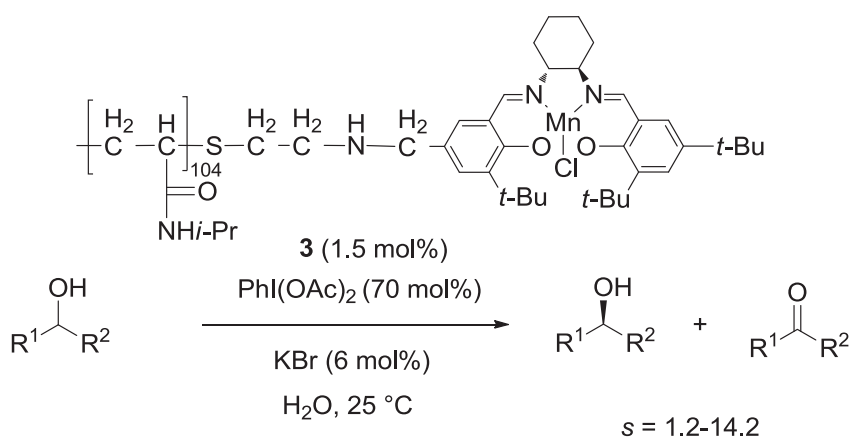

$\mathrm{R}^{1}=\mathrm{Ph}, \mathrm{R}^{2}=\mathrm{Me}: 63 \%$ conversion, $96 \%$ ee

$\mathrm{R}^{1}=\mathrm{Ph}, \mathrm{R}^{2}=\mathrm{Et}: 54 \%$ conversion, $7 \%$ ee

$\mathrm{R}^{1}=p$-Tol, $\mathrm{R}^{2}=\mathrm{Me}: 63 \%$ conversion, $90 \%$ ee

$\mathrm{R}^{1}=0-$ Tol, $\mathrm{R}^{2}=\mathrm{Me}: 17 \%$ conversion, $8 \%$ ee

$\mathrm{R}^{1}=p-\mathrm{ClC}_{6} \mathrm{H}_{4}, \mathrm{R}^{2}=\mathrm{Me}: 52 \%$ conversion, $56 \%$ ee

$\mathrm{R}^{1}=m-\mathrm{ClC}_{6} \mathrm{H}_{4}, \mathrm{R}^{2}=\mathrm{Me}: 40 \%$ conversion, $29 \%$ ee

$\mathrm{R}^{1}=0-\mathrm{ClC}_{6} \mathrm{H}_{4}, \mathrm{R}^{2}=\mathrm{Me}: 15 \%$ conversion, $5 \%$ ee

$\mathrm{R}^{1}=p-\mathrm{BrC}_{6} \mathrm{H}_{4}, \mathrm{R}^{2}=\mathrm{Me}: 59 \%$ conversion, $92 \%$ ee

$\mathrm{R}^{1}=\mathrm{Me}, \mathrm{R}^{2}=n-\operatorname{Pr}: 63 \%$ conversion, $94 \%$ ee

Scheme 4. Oxidative kinetic resolution of secondary alcohols catalysed with a salen manganese complex bearing a thermoregulated phase-transfer function. 
manganese complex 4 that was applied to promote the oxidative kinetic resolution of 1 -phenylethanol. ${ }^{22}$ The process was performed in water by using $\mathrm{PhI}(\mathrm{OAc})_{2}$ as oxidant and allowed the chiral alcohol to be achieved in 54\% conversion, $88 \%$ ee, and a selectivity factor of 19.2 (Scheme 5 ).

\subsection{Using oxidants other than $\mathrm{PhI}(\mathrm{OAc})_{2}$}

In addition to expensive $\mathrm{PhI}(\mathrm{OAc})_{2}$, other oxidants have been used to promote oxidative kinetic resolutions of secondary alcohols catalysed with chiral manganese complexes. For example in 2012, Sun et al. introduced the use of cheap and readily available $N$ bromo succinimide (NBS) as oxidant. ${ }^{23}$ As shown in Scheme 6, this new protocol was catalysed with $1 \mathrm{~mol} \%$ of chiral salen manganese complex $\mathbf{5}$ in a mixture of dichloromethane and water as solvent. It was found very efficient under mild reaction conditions since a wide range of chiral aromatic and aliphatic alcohols were obtained in generally high enantioselectivities (86->99\% ee) and good conversions (56-64\%). Remarkably, challenging ortho-substituted benzylic alcohols also provided excellent results (93-99\% ee) except 1-(2-methoxyphenyl)ethanol $\left(\mathrm{R}=0-\mathrm{MeOC}_{6} \mathrm{H}_{4}\right)$ which gave a moderate enantioselectivity of $56 \%$ ee.

In order to further improve the performance of their novel macrocyclic chiral salen manganese complex 1 reported in 2013 (Scheme 2), Abdi et al. also investigated the use of NBS as oxidant in these reactions in place of $\mathrm{PhI}(\mathrm{OAc})_{2} \cdot{ }^{18}$ Remarkably, the oxidative kinetic resolution of a variety of aliphatic and aromatic secondary alcohols performed at $20^{\circ} \mathrm{C}$ in aqueous dichloromethane as solvent in the presence of KOAc as additive provided uniformly excellent enantioselectivities (88->99\% ee) combined with good conversions (64-67\%), as shown in Scheme 7. In all cases of substrates studied, the enantioselectivities were much higher by using NBS than $\mathrm{PhI}(\mathrm{OAc})_{2}$ as oxidant.

In 2014, Zhao et al. reported another alternative to the use of expensive $\mathrm{PhI}(\mathrm{OAc})_{2}$ as oxidant in these reactions with the use of cheap and easy available sodium hypochlorite $(\mathrm{NaClO}){ }^{24}$ The process was performed in the presence of $1 \mathrm{~mol} \%$ of salen manganese catalyst $\mathbf{6}$ in a mixture of dichloromethane and water as solvent. It also required $6 \mathrm{~mol} \%$ of $\mathrm{Br}_{2}$ as additive. The $\mathrm{Br}^{-}$from $\mathrm{Br}_{2}$ replaced $\mathrm{Cl}^{-}$in catalyst 6 to give the corresponding brominated complex that further reacted with $\mathrm{Br}_{2}$ to generate a dibromo-Mn(V) species and $\mathrm{HBr}$. Then, the generated $\mathrm{HBr}$ was oxidised by $\mathrm{NaClO}$ to regenerate $\mathrm{Br}_{2}$. This system was compatible to a variety of secondary alcohols with moderate to good conversions (30-62\%) and

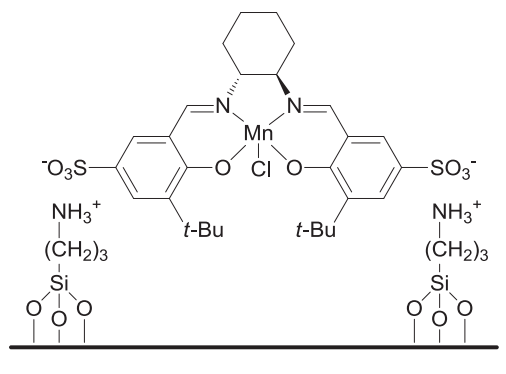

4

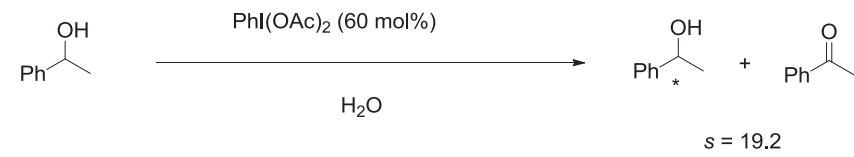

$54 \%$ conversion, $88 \%$ ee

Scheme 5. Oxidative kinetic resolution of 1-phenylethanol catalysed with a mesoporous helical silica immobilised salen manganese complex.

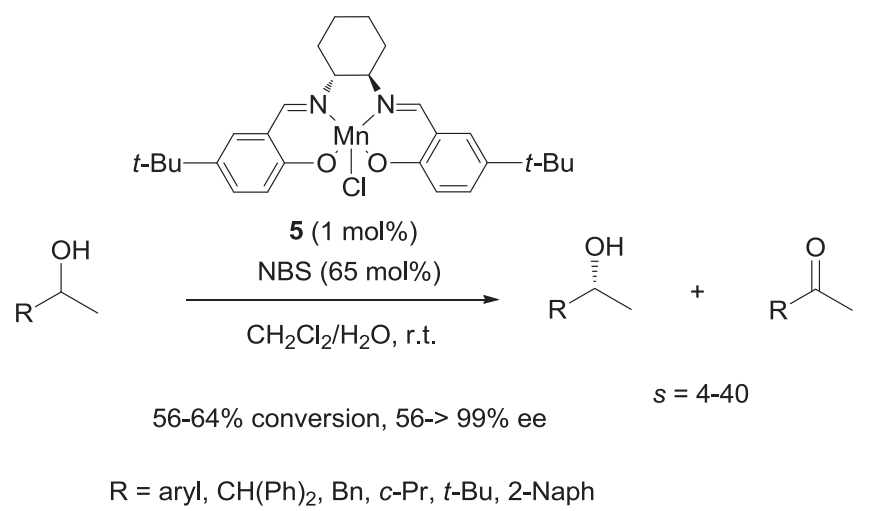

Scheme 6. Oxidative kinetic resolution of secondary alcohols catalysed with a salen manganese complex and using NBS as oxidant.

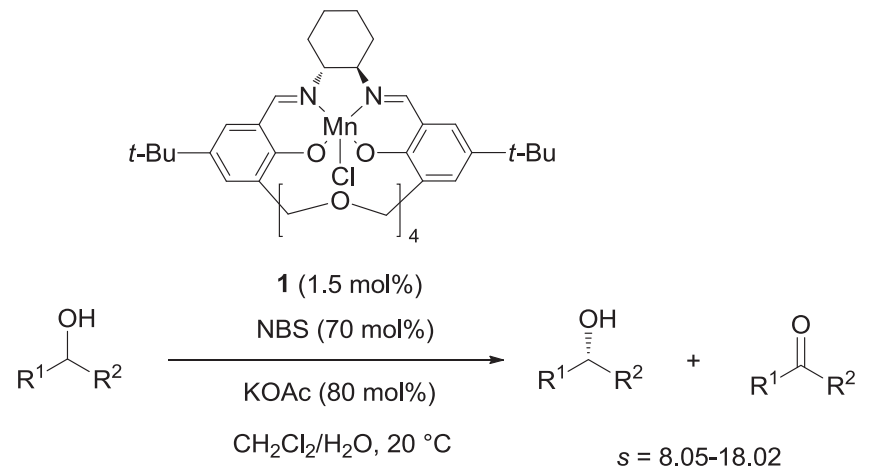

$\mathrm{R}^{1}=\mathrm{Ph}, \mathrm{R}^{2}=\mathrm{Me}: 64 \%$ conversion, $>99 \%$ ee

$\mathrm{R}^{1}=p$-Tol, $\mathrm{R}^{2}=\mathrm{Me}: 65 \%$ conversion, $96 \%$ ee

$\mathrm{R}^{1}=p-\mathrm{ClC}_{6} \mathrm{H}_{4}, \mathrm{R}^{2}=\mathrm{Me}: 67 \%$ conversion, $98 \%$ ee

$\mathrm{R}^{1}=p-\mathrm{BrC}_{6} \mathrm{H}_{4}, \mathrm{R}^{2}=\mathrm{Me}: 64 \%$ conversion, $97 \%$ ee

$\mathrm{R}^{1}=p-\mathrm{FC}_{6} \mathrm{H}_{4}, \mathrm{R}^{2}=\mathrm{Me}: 66 \%$ conversion, $96 \%$ ee

$\mathrm{R}^{1}=p-\mathrm{MeOC}_{6} \mathrm{H}_{4}, \mathrm{R}^{2}=\mathrm{Me}: 64 \%$ conversion, $88 \%$ ee

$\mathrm{R}^{1}=\mathrm{Ph}, \mathrm{R}^{2}=\mathrm{Et}: 66 \%$ conversion, $>99 \%$ ee

$\mathrm{R}^{1}=\mathrm{Bn}, \mathrm{R}^{2}=\mathrm{Me}: 65 \%$ conversion, $97 \%$ ee

$\mathrm{R}^{1}=\mathrm{CH}_{2} \mathrm{Bn}, \mathrm{R}^{2}=\mathrm{Me}: 64 \%$ conversion, $94 \%$ ee

$\mathrm{R}^{1}=\mathrm{Et}, \mathrm{R}^{2}=$ Me: $67 \%$ conversion, $97 \%$ ee

Scheme 7. Oxidative kinetic resolution of secondary alcohols catalysed with a macrocyclic manganese salen complex and using NBS as oxidant.

enantioselectivities (20-97\% ee), as shown in Scheme 8. The best enantioselectivities were generally achieved in the reaction of 1phenylethanol derivatives, including a sterically hindered orthosubstituted substrate $\left(\mathrm{R}^{1}=0-\mathrm{ClC}_{6} \mathrm{H}_{4}, \mathrm{R}^{2}=\mathrm{Me}\right)$ which provided an enantioselectivity of $82 \%$ ee. The lowest enantioselectivity (20\% ee) and conversion $(30 \%)$ were obtained in the reaction of 1-(paramethoxyphenyl)-1-ethanol. However, the main disadvantage of this system was the handling of the rather toxic and corrosive $\mathrm{Br}_{2}$. To address this issue, the same authors replaced this reagent by NBS in the same reactions. ${ }^{25}$ Performed with the same catalyst, oxidant and solvent at room temperature, the reactions provided good conversions of up to $62 \%$ along with high enantioselectivities of up to $>99 \%$ ee.

Always the same year, NBS was also employed as oxidant by Kureshy et al. in oxidative kinetic resolutions of secondary benzylic alcohols catalysed by novel macrocyclic diethyl tartrate-linked salen manganese complexes. ${ }^{26}$ As shown in Scheme 9, using $1.5 \mathrm{~mol} \%$ of the optimal catalyst $\mathbf{7}$ in the usual biphasic solvent 


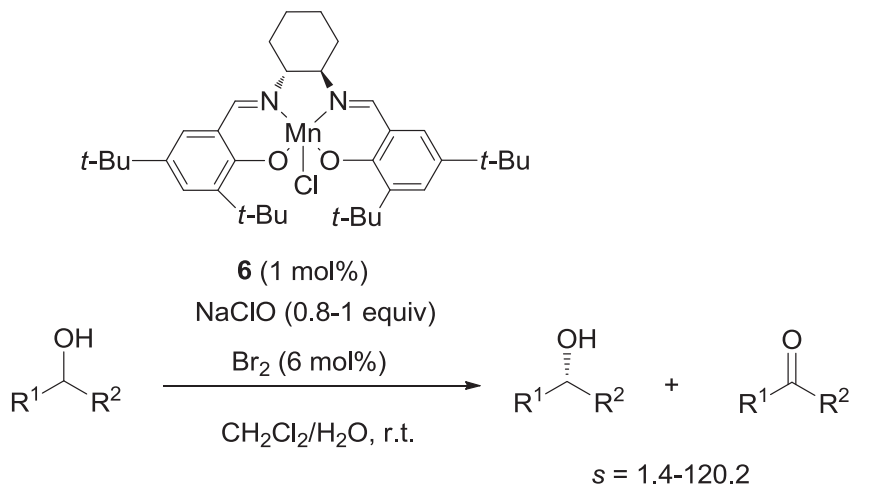

$30-62 \%$ conversion, $20-97 \%$ ee

$\mathrm{R}^{1}=$ aryl, 2-Naph

$\mathrm{R}^{2}=\mathrm{Me}, \mathrm{Et}, i-\mathrm{Pr}, n-\mathrm{Bu}$

Scheme 8. Oxidative kinetic resolution of secondary alcohols catalysed with a salen manganese complex and using $\mathrm{NaClO}$ as oxidant.

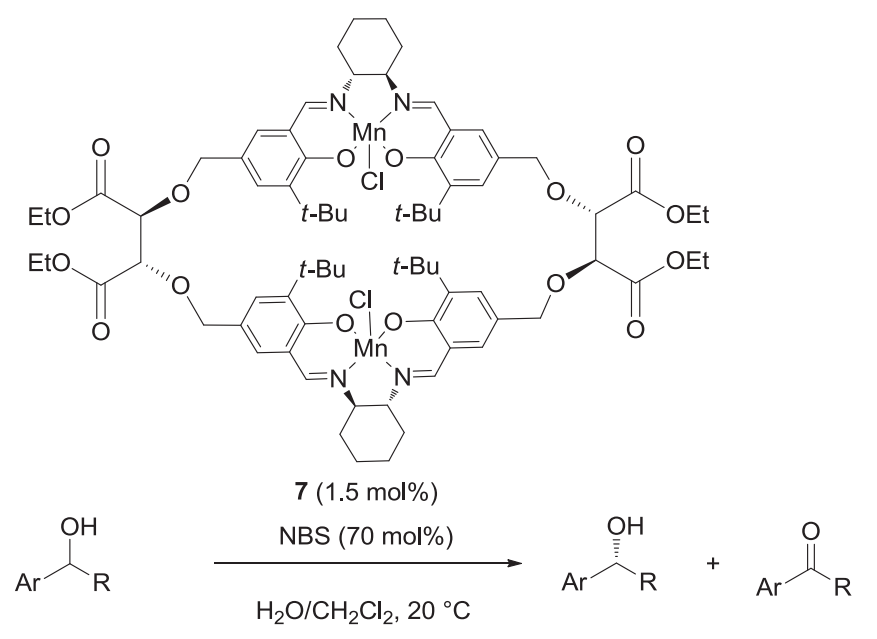

$\mathrm{Ar}=\mathrm{Ph}, \mathrm{R}=\mathrm{Me}: 66 \%$ conversion, $95 \%$ ee

$\mathrm{Ar}=p-\mathrm{FC}_{6} \mathrm{H}_{4}, \mathrm{R}=\mathrm{Me}: 96 \%$ ee

$\mathrm{Ar}=p-\mathrm{ClC}_{6} \mathrm{H}_{4}, \mathrm{R}=\mathrm{Me}: 93 \%$ ee

$\mathrm{Ar}=p-\mathrm{Tol}, \mathrm{R}=\mathrm{Me}: 84 \%$ ee

$\mathrm{Ar}=p-\mathrm{BrC}_{6} \mathrm{H}_{4}, \mathrm{R}=\mathrm{Me}: 85 \%$ ee

$\mathrm{Ar}=\mathrm{Ph}, \mathrm{R}=\mathrm{Et}$ : $65 \%$ conversion, $97 \%$ ee

Scheme 9. Oxidative kinetic resolution of secondary benzylic alcohols catalysed with a diethyl tartrate-linked macrocyclic manganese salen complex and using NBS as oxidant.

allowed several chiral benzylic alcohols to be obtained with good conversions of up to $66 \%$ and enantioselectivities of up to $97 \%$ ee.

In 2017, Bryliakov et al. reported the first use of $\mathrm{H}_{2} \mathrm{O}_{2}$ as more environmentally benign oxidant in the oxidative kinetic resolution of secondary alcohols. ${ }^{27}$ The process was based on the use of a manganese complex not derived from a salen ligand but from a tetradentate aminopyridine ligand. As shown in Scheme 10, the reaction employed a very low catalyst loading of $0.06-0.1 \mathrm{~mol} \%$ of manganese complex 8 in acetonitrile at $-10^{\circ} \mathrm{C}$ without any additive. Variously para-substituted 1-phenylethanols were compatible, leading to the corresponding chiral alcohols with moderate to good conversions (34-59\%), low to high enantioselectivities (22-95\% ee) and selectivity factors of 2-7.6, while unsubstituted (S)-1phenylethanol was obtained in 53\% conversion and 61\% ee. Very recently, the same authors investigated the influence of

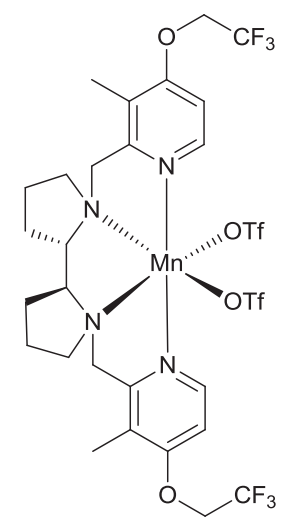

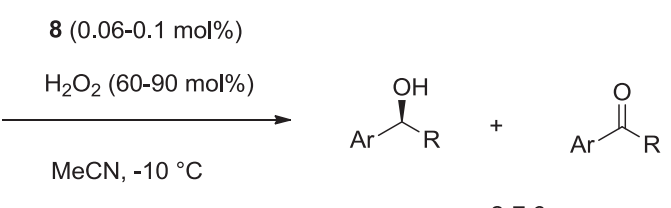

$s=2-7.6$

$34-59 \%$ conversion, $22-95 \%$ ee

$\mathrm{Ar}=\mathrm{Ph}, p-\mathrm{ClC}_{6} \mathrm{H}_{4}, p-\mathrm{MeOC}_{6} \mathrm{H}_{4}, p-\mathrm{Tol}, p-\mathrm{FC}_{6} \mathrm{H}_{4}, p-\mathrm{CF}_{3} \mathrm{C}_{6} \mathrm{H}_{4}$ $\mathrm{R}=\mathrm{Me}, \mathrm{Bn}$

Scheme 10. Oxidative kinetic resolution of secondary benzylic alcohols catalysed with another tetradentate aminopyridine manganese complex and using $\mathrm{H}_{2} \mathrm{O}_{2}$ as oxidant.

asymmetric autoamplification on these reactions, using various substrates. ${ }^{28}$ In some cases of substrates, the selectivity factor was found to vary non-constantly over the reaction course. Therefore, for relatively small secondary alcohols (1-phenylethanol, 1-p-tolylethanol), the selectivity factor monotonously increased over the reaction course up to substrate conversions of $70 \%$. For bulkier alcohols or alkyl mandelates, the growth of the selectivity factor was less pronounced and changed into decay at moderate conversions of $50-60 \%$. An exception was the bulkiest 1-(2-naphthyl)ethanol for which the selectivity factor monotonously declined over the reaction course.

Soon after the early work published by Bryliakov in 2017, Sun et al. developed comparable reactions by using manganese complex 9 derived from another tetradentate aminopyridine ligand employed at a low catalyst loading of $0.2 \mathrm{~mol} \%{ }^{29}$ The process was promoted at $0{ }^{\circ} \mathrm{C}$ in acetonitrile as solvent in the presence of $\mathrm{H}_{2} \mathrm{SO}_{4}$ as additive. As shown in Scheme 11, a range of secondary benzylic alcohols were compatible, giving uniformly excellent enantioselectivities (90-96\% ee) and high conversions (60-74\%). This remarkable green methodology presented several advantages, such as the use of an environmentally benign oxidant, the use of a very low catalyst loading and the obtaining of uniformly very high enantioselectivities.

\section{Palladium-catalysed oxidative kinetic resolutions of secondary alcohols}

The prospect of using oxygen from air as the direct and primary oxidant for the oxidative kinetic resolution of alcohols makes it especially attractive from a green point of view. In this context, aerobic oxidative kinetic resolution methods were independently developed by the groups of Stoltz and Sigman since 2001, on the basis of palladium catalysis in the presence of sparteine as a chiral ligand. The application of this methodology has allowed in the last years the achievement of successful oxidative kinetic resolutions of a number of benzylic, allylic and cyclopropyl secondary alcohols in 


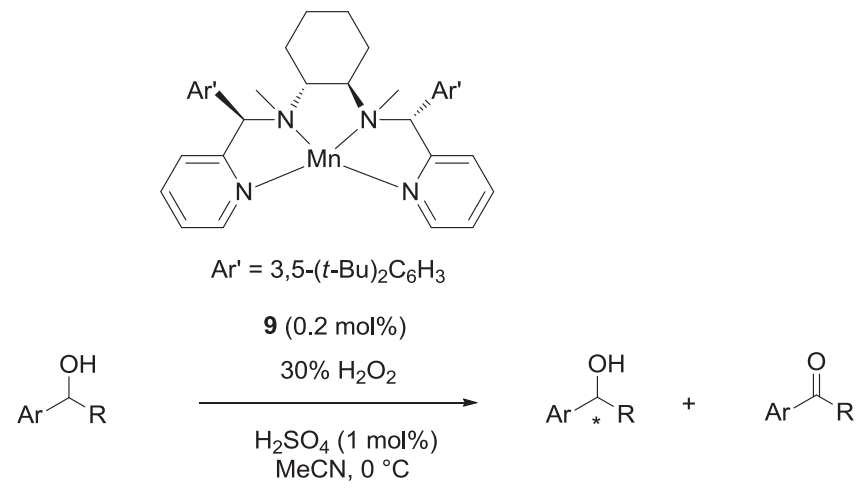

$60-74 \%$ conversion, $90-96 \%$ ee

$\mathrm{Ar}=\mathrm{Ph}, p-\mathrm{ClC}_{6} \mathrm{H}_{4}, m-\mathrm{ClC}_{6} \mathrm{H}_{4}, o-\mathrm{ClC}_{6} \mathrm{H}_{4}, p-\mathrm{O}_{2} \mathrm{NC}_{6} \mathrm{H}_{4}$, $p-\mathrm{PhC}_{6} \mathrm{H}_{4}, p-\mathrm{BrC}_{6} \mathrm{H}_{4}, p-\mathrm{FC}_{6} \mathrm{H}_{4}, m-\mathrm{FC}_{6} \mathrm{H}_{4}, o-\mathrm{FC}_{6} \mathrm{H}_{4}$ $\mathrm{R}=\mathrm{Me}, \mathrm{Cy}, n-\mathrm{Hex}, i-\mathrm{Pr}$

Scheme 11. Oxidative kinetic resolution of secondary benzylic alcohols catalysed by a manganese complex derived from a tetradentate aminopyridine ligand and using $\mathrm{H}_{2} \mathrm{O}_{2}$ as oxidant.

good to high selectivity factors of up to $122 .{ }^{30}$ Different sparteine surrogates, such as 9-oxabispidines, were also successfully applied by several groups to promote these reactions. ${ }^{31}$ In 2013 , Stoltz et al. reported the synthesis of a key intermediate in the synthesis of the naturally occurring anti-cancer agent bielschowskysin based on a palladium-catalysed oxidative kinetic resolution performed under oxygen atmosphere. ${ }^{32}$ As shown in Scheme 12, the treatment of a racemic functionalised secondary alcohol by a combination of $5 \mathrm{~mol}$ $\%$ of $\mathrm{Pd}(\mathrm{nbd}) \mathrm{Cl}_{2}$ and $20 \mathrm{~mol} \%$ of (-)-sparteine in toluene at $80^{\circ} \mathrm{C}$ led to the almost enantiopure ( $3 R, 5 S)$-alcohol $(>95 \%$ ee) with a high selectivity factor $(s=23)$ along with the corresponding $(3 S)$-ketone in $57 \%$ conversion.

Due to the difficulty in controlling the regioselectivity, the nonenzymatic kinetic resolution of unprotected diols is still undeveloped. ${ }^{6 \mathrm{~d}}$ In this context, Hua et al. reported in 2016 the synthesis of novel chiral-substituted poly- $N$-vinylpyrrolidinones to be applied as chiral ligands in the aerobic oxidative kinetic resolution of trans1,3- and 1,2-cycloalkanediols catalysed with a bimetallic $(\mathrm{Pd} / \mathrm{Au})$

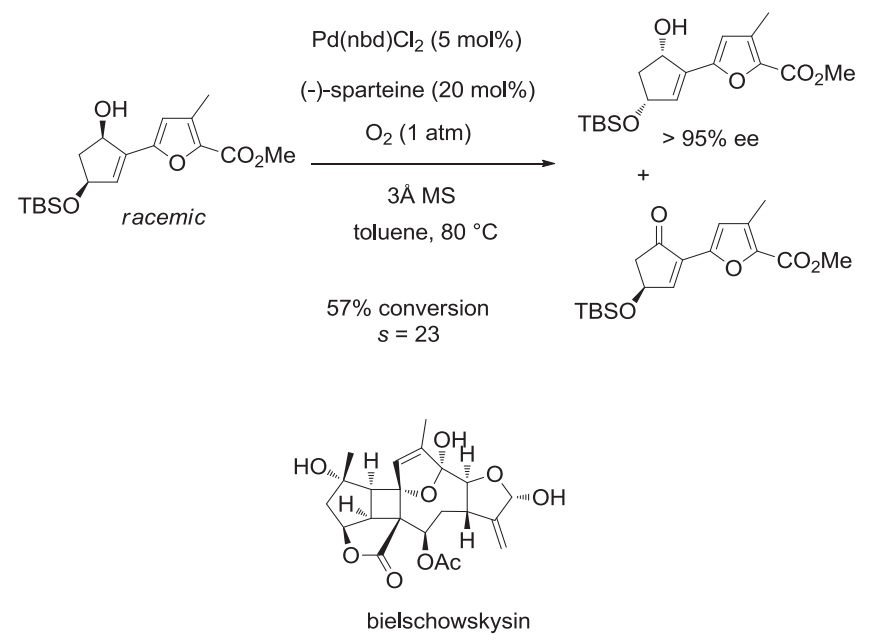

Scheme 12. Aerobic oxidative kinetic resolution of a functionalised alcohol catalysed with a (-)-sparteine-derived palladium complex. nanocluster derived from polymeric chiral pyrrolidinone $\mathbf{1 0}$ and performed under oxygen atmosphere in water. ${ }^{33}$ Indeed, when this catalyst system was employed at only $0.15 \mathrm{~mol} \%$ of catalyst loading in water in the presence of $\mathrm{K}_{2} \mathrm{CO}_{3}$ to promote the oxidative kinetic resolution of a range of racemic trans-1,3-cycloalkanediols, it provided the corresponding $(S)$-ketones in good to excellent enantioselectivities (83-99\% ee) and good yields (46-49\%) along with $(R, R)$-trans-1,3-cycloalkanediols in good to high enantioselectivities (79-92\% ee) and good yields (50-53\%), as shown in Scheme 13 (first equation). The process was also compatible to trans-1,2cycloalkanediols which allowed the corresponding enantiopure (S)-ketones (99\% ee) to be achieved in good yields (45-47\%) and $(R, R)$-trans-1,2-cycloalkanediols with good enantioselectivities (87-88\% ee) and yields (50-54\%), as shown in Scheme 13 (second equation).

\section{Oxidative kinetic resolutions of secondary alcohols catalysed with other metals}

Chiral vanadium complexes have also been successfully applied as catalysts to promote oxidative kinetic resolutions of various types of functionalised secondary alcohols, including $\alpha$-hydroxy esters, $\alpha$-hydroxy phosphonates and $\alpha$-hydroxy amides under oxygen atmosphere with selectivity factors of up to $1057 .{ }^{34}$ In 2011, Chen et al. described the first efficient immobilisation of C5propargyl ether-modified chiral $\mathrm{N}$-salicylidene vanadyl(V) tertleucinates onto azido-functionalised polystyrene through click chemistry. ${ }^{35}$ As shown in Scheme 14, polystyrene-supported vanadium catalyst $\mathbf{1 1}$ was found to be capable of promoting the oxidative kinetic resolution under oxygen atmosphere of a wide range of $\alpha$-hydroxy (thio)esters and $\alpha$-hydroxy amides with generally high enantioselectivities of up to $99 \%$ ee, moderate yields (33-43\%) and selectivity factors of 3-24. Uniformly high enantioselectivities (87-96\% ee) were obtained for mandelates and a $\alpha$ hydroxy (thio)ester as substrates. Comparable excellent enantioselectivities (80-99\% ee) were achieved in the kinetic resolution of various benzyl $\alpha$-hydroxy amides $\left(\mathrm{R}^{2}=\mathrm{NHBn}\right)$ bearing different $\alpha$ aryl and alkyl groups $\left(R^{1}\right)$. A lower enantioselectivity of $44 \%$ ee was exceptionally observed in the reaction of a substrate exhibiting a $\alpha$ isopropyl group $\left(\mathrm{R}^{1}=i-\mathrm{Pr}\right)$. It must be noted that the catalyst could
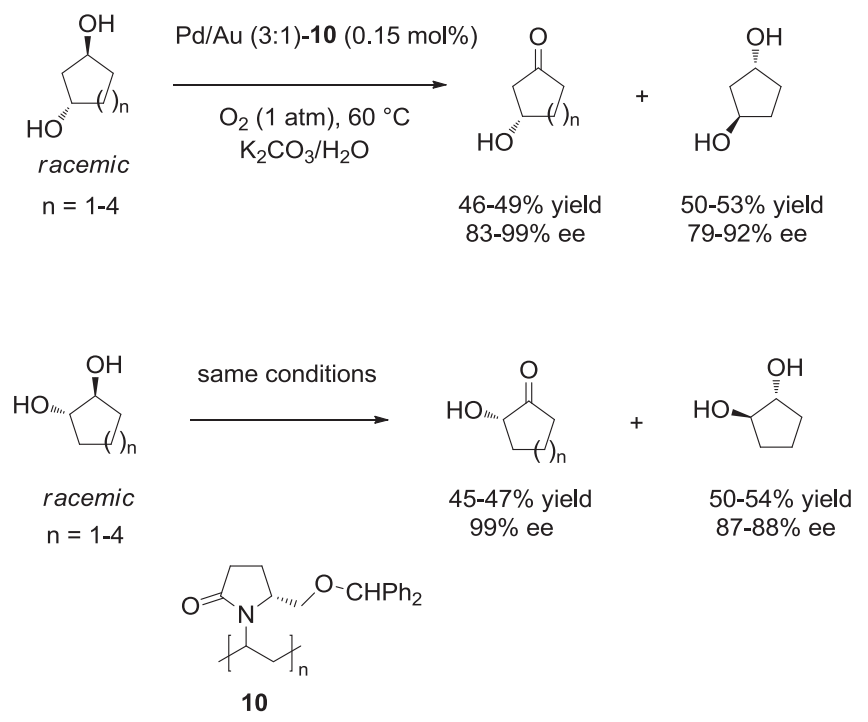

Scheme 13. Aerobic oxidative kinetic resolutions of trans-1,3- and 1,2-cycloalkanediols catalysed with a Pd/Au (3:1) nanocluster derived from a chiral-substituted poly- $\mathrm{N}$ vinylpyrrolidinone. 


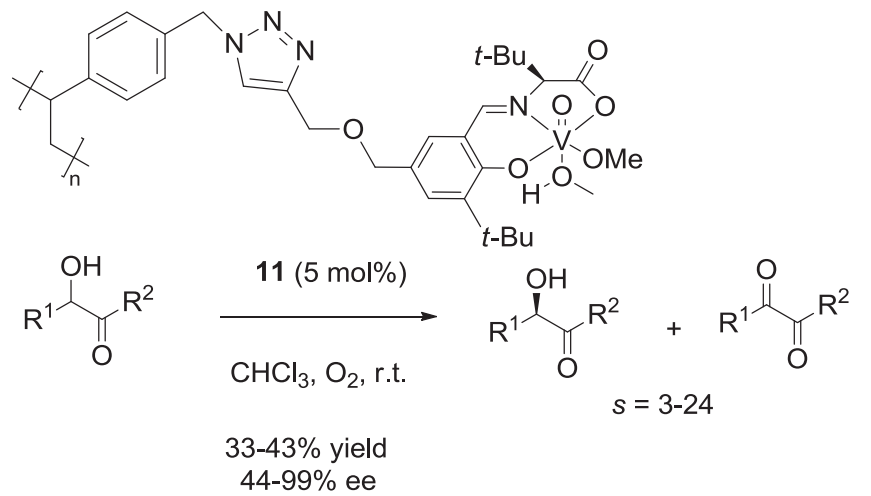

$\mathrm{R}^{1}=\mathrm{Ph}, p-\mathrm{Tol}, p-\mathrm{ClC}_{6} \mathrm{H}_{4}, p-\mathrm{F}_{3} \mathrm{CC}_{6} \mathrm{H}_{4}, o-\mathrm{Tol}, o-\mathrm{ClC}_{6} \mathrm{H}_{4}, 1-\mathrm{Naph}$, 2-thiophenyl, $(E)-\mathrm{PhCH}=\mathrm{CH}, c-\operatorname{Pr}, i-\mathrm{Pr}$

$\mathrm{R}^{2}=\mathrm{OBn}, \mathrm{OMe}, \mathrm{OEt}, \mathrm{O} i-\mathrm{Pr}, \mathrm{SBn}, \mathrm{NHBn}, \mathrm{NHCH}(\mathrm{Ph})_{2}, \mathrm{NH} i-\mathrm{Pr}$

Scheme 14. Aerobic oxidative kinetic resolution of $\alpha$-hydroxy (thio)esters and $\alpha$-hydroxy amides catalysed with a polystyrene-supported $\mathrm{N}$-salicylidene vanadyl(V) carboxylate catalyst.

be readily recovered by simple filtration and reused without loss of activity and enantioselectivity for at least four runs.

Different types of chiral ruthenium complexes have also been proved to be efficient catalysts in these reactions. ${ }^{36}$ For example in 2014, Katsuki et al. demonstrated that oxidative kinetic resolutions of secondary alcohols could be performed under air atmosphere in the presence of chiral aqua salen ruthenium complex 12 (Scheme 15). ${ }^{37}$ A range of aromatic as well as aliphatic alcohols were compatible to the process, providing enantioselectivities of up to $>98 \%$ ee. Generally, the highest selectivity factors (up to 60) were achieved in the reactions of activated alcohols, such as benzylic

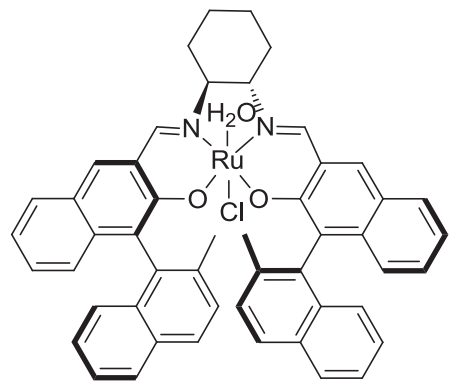

$12(2 \mathrm{~mol} \%)$

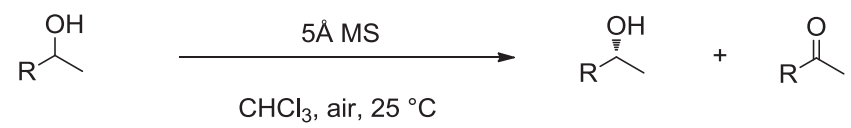

$\mathrm{R}=\mathrm{Ph}, p-\mathrm{ClC}_{6} \mathrm{H}_{4}, p-\mathrm{BrC}_{6} \mathrm{H}_{4}, p-\mathrm{MeO}_{2} \mathrm{CC}_{6} \mathrm{H}_{4}, p-\mathrm{F}_{3} \mathrm{CC}_{6} \mathrm{H}_{4}, p-\mathrm{MeOC}_{6} \mathrm{H}_{4}$ $p$-Tol, o- $\mathrm{ClC}_{6} \mathrm{H}_{4}, o-\mathrm{BrC}_{6} \mathrm{H}_{4}, o-\mathrm{MeOC}_{6} \mathrm{H}_{4}, o-\mathrm{Tol}, m-\mathrm{ClC}_{6} \mathrm{H}_{4}, m-\mathrm{BrC}_{6} \mathrm{H}_{4}$, $m-\mathrm{MeOC}_{6} \mathrm{H}_{4}, m-\mathrm{Tol}, 1-\mathrm{Naph}: s=9-60$

$\mathrm{R}=\mathrm{BnCH}_{2}, \mathrm{Cy}, c-$ Pent, $n$-Hex, $n-\mathrm{Bu}, \mathrm{TBSOCH}_{2},(E)-\mathrm{PhCH}=\mathrm{CH}$,

$(E)-\mathrm{EtCH}=\mathrm{CMe}: s=12-26$

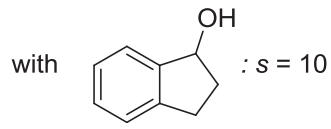

Scheme 15. Aerobic oxidative kinetic resolution of secondary alcohols catalysed with an aqua salen ruthenium complex. ones bearing a substituent at the para-, meta- or ortho-position, while selectivity factors of $12-26$ were obtained for more challenging aliphatic alcohols including allylic ones.

Chiral iron complexes are also efficient catalysts to promote oxidative kinetic resolutions of secondary alcohols. ${ }^{38}$ In 2011, Katsuki et al. reported the first general method for iron-catalysed aerobic oxidative kinetic resolution of secondary alcohols. ${ }^{39}$ It was based on the use of $3 \mathrm{~mol} \%$ of salen iron complex 13 in toluene at $50^{\circ} \mathrm{C}$ in the presence of 1-naphthol as additive. As shown in Scheme 16, the process allowed a wide range of chiral alcohols to be prepared in good conversions (52-62\%) and good to excellent enantioselectivities (67-99\% ee). For example, regardless of the electronic nature of the aryl group of alcohols, a series of secondary benzylic alcohols were enantiomerically differentiated with uniformly excellent enantioselectivities (90-97\% ee). Surprisingly, a lower enantioselectivity (73\% ee) was obtained in the kinetic resolution of 1-phenylethanol. Notably, 1-(2-naphthyl)ethanol was also smoothly resolved with $94 \%$ ee. Moreover, cyclic carbinols were also oxidised, although the observed enantioselectivities (67-88\% ee) were found dependent on the ring size of the substrates. The reaction of alkenyl carbinols were also highly enantioselective (90\% ee) as well as that of nonactivated dialkyl alcohols which provided good to excellent enantioselectivities (86-99\% ee).

Very good results have also been described by using chiral iridium catalysts in these reactions. ${ }^{40}$ As an example, Gao et al. reported in 2012 the use of an iridium catalyst in situ generated from $0.5 \mathrm{~mol} \%$ of $[\mathrm{IrCl}(\operatorname{cod})]_{2}$ and $5 \mathrm{~mol} \%$ of chiral diaminodiphosphine ligand $\mathbf{1 4}$ in the green oxidative kinetic resolution of aromatic secondary alcohols performed in water. ${ }^{41}$ As illustrated in Scheme 17, this environmentally benign process performed between 18 and $45^{\circ} \mathrm{C}$ employed acetone as oxidant and $\mathrm{KOH}$ as base. A range of aromatic secondary alcohols smoothly reacted under this mild conditions with good conversions (51-65\%) and good to excellent enantioselectivities (62-97\% ee). Racemic 1phenylethanol and its derivatives were compatible $(\mathrm{R}=\mathrm{Me}, \mathrm{Et}, n-$ $\mathrm{Pr}, n$-Bu), giving uniformly very high enantioselectivities (90-97\% ee), however, when the alkyl substituent $(R)$ of the substrate was substituted with a bulkier group, the reaction proceeded slowly with slightly lower enantioselectivities ( $\mathrm{R}=i$-Pr: $89 \%$ ee). On the other hand, an unexpected excellent enantioselectivity of $97 \%$ ee

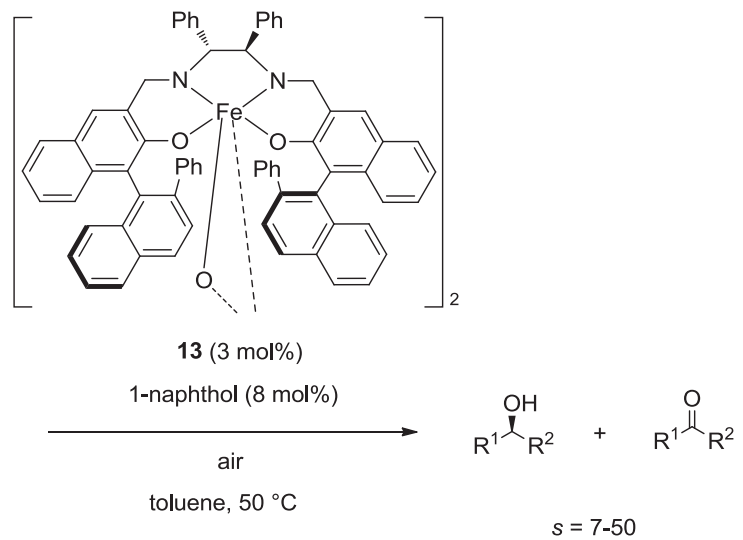

$52-62 \%$ conversion, $67-99 \%$ ee

$\mathrm{R}^{1}=\mathrm{Ph}, p-\mathrm{MeOC}_{6} \mathrm{H}_{4}, p-\mathrm{Me}_{2} \mathrm{NC}_{6} \mathrm{H}_{4}, p-\mathrm{CNC}_{6} \mathrm{H}_{4}, p-\mathrm{ClC}_{6} \mathrm{H}_{4}, p-\mathrm{CF}_{3} \mathrm{C}_{6} \mathrm{H}_{4}$, 2-Naph, 1-hydroxyindan, 1-hydroxytetralin, 1-hydroxybenzosuberan, $(E)-\mathrm{PhCH}=\mathrm{CH}, \mathrm{BnCH}_{2}, c-$ Pent

$\mathrm{R}^{2}=\mathrm{Me}, \mathrm{Et}$

Scheme 16. Aerobic oxidative kinetic resolution of secondary alcohols catalysed with a salen iron complex. 


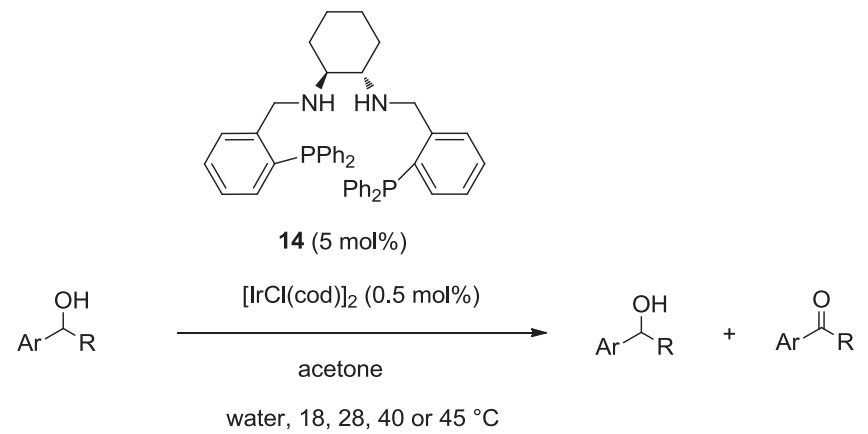

$51-65 \%$ conversion, $62-97 \%$ ee

$\mathrm{Ar}=\mathrm{Ph}, p-\mathrm{MeOC}_{6} \mathrm{H}_{4}, p-\mathrm{ClC}_{6} \mathrm{H}_{4}, p-\mathrm{Tol}, m-\mathrm{ClC}_{6} \mathrm{H}_{4}, m-\mathrm{MeOC}_{6} \mathrm{H}_{4}, m-\mathrm{Tol}$ $\mathrm{R}=\mathrm{Me}, \mathrm{Et}, n-\mathrm{Pr}, n-\mathrm{Bu}, i-\mathrm{Pr}, \mathrm{Cy}, \mathrm{CHPh}_{2}$

$$
\text { with }: 65 \% \text { conversion, } 80 \% \text { ee }
$$

Scheme 17. Iridium-catalysed oxidative kinetic resolution of secondary aromatic alcohols.

was achieved in the reaction of a sterically hindered substrate $(\mathrm{R}=\mathrm{Cy}, \mathrm{Ar}=\mathrm{Ph})$. Concerning the aromatic group of the substrate, it was found that the introduction of a substituent at the ortho position of the phenyl group prevented the reaction to occur $(\mathrm{Ar}=0$ $\mathrm{ClC}_{6} \mathrm{H}_{4}, o-\mathrm{MeOC}_{6} \mathrm{H}_{4}, o$-Tol). However, the presence of an electrondonating group at the meta or para positions of the aromatic moiety of the substrate $\left(\mathrm{Ar}=p\right.$-Tol, $m$-Tol, $\left.p-\mathrm{MeOC}_{6} \mathrm{H}_{4}, m-\mathrm{MeOC}_{6} \mathrm{H}_{4}\right)$ led to excellent enantioselectivities (91-97\% ee) while lower enantioselectivities (62-64\% ee) were obtained when a chloro substituent was at these positions $\left(\mathrm{Ar}=p-\mathrm{ClC}_{6} \mathrm{H}_{4}, m-\mathrm{ClC}_{6} \mathrm{H}_{4}\right)$.

Chiral complexes derived from other metal, including cobalt, ${ }^{42}$ and cheaper copper ${ }^{43}$ also provided excellent results. Among them, Wu et al. described in 2014 the synthesis of chiral surfactants exhibiting two long alkyl chains with hydroxyl groups at their terminals which were further employed to encapsulate a polyoxometalate through electrostatic interaction. ${ }^{44}$ The thus formed chiral surfactant-encapsulated polyoxometalate complexes were further covalently immobilised on silica. The thus formed chiral supramolecular hybrid catalyst was found efficient to promote the oxidative kinetic resolution of 1-phenylethanol with high enantioselectivity ( $89 \%$ ee).

\section{Organocatalysed oxidative kinetic resolutions of secondary alcohols}

In 2009, the first highly enantioselective organocatalytic oxidative kinetic resolution of unactivated aliphatic secondary alcohols was accomplished by Iwabuchi et al. by using chirally modified 2-azaadamantane $\mathrm{N}$-oxyls as organocatalysts in the presence of trichloroisocyanuric acid (TCCA) as oxidant, which allowed selectivity factors of up to 82.2 to be obtained. ${ }^{45}$ Ever since, other types of organocatalysts have been investigated in these reactions. ${ }^{46}$ For example in 2014 , Iwabuchi et al. widely extended the scope of their early methodology. ${ }^{47}$ As shown in Scheme 18 (first equation), a number of unactivated cis- and trans- $\alpha$-substituted cycloalkanols $\left(\mathrm{X}=\mathrm{CH}_{2}, \mathrm{n}=1-3\right)$ were resolved with good

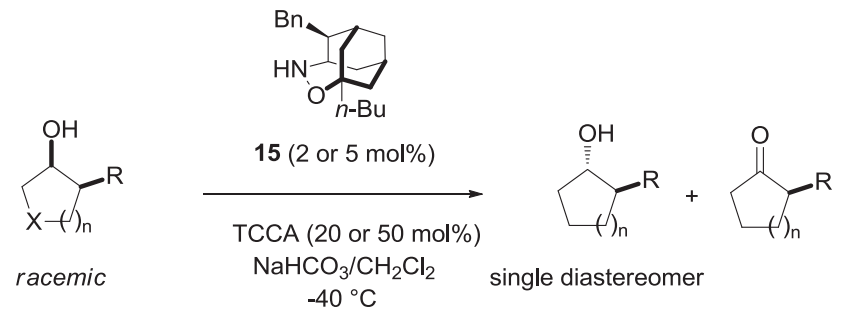

$51-66 \%$ conversion, $3-99 \%$ ee, $s=1.8-297$

$\mathrm{R}=\mathrm{Ph}, p-\mathrm{FC}_{6} \mathrm{H}_{4}, p-\mathrm{ClC}_{6} \mathrm{H}_{4}, p-\mathrm{Tol}, p-\mathrm{MeOC}_{6} \mathrm{H}_{4}, p-\mathrm{MsOC}_{6} \mathrm{H}_{4}, \mathrm{OAc}, \mathrm{OBz}, i-\mathrm{Pr}$ $\mathrm{X}=\mathrm{CH}_{2}, \mathrm{O}, \mathrm{NCbz}, \mathrm{NBoc}$ $\mathrm{n}=1-3$

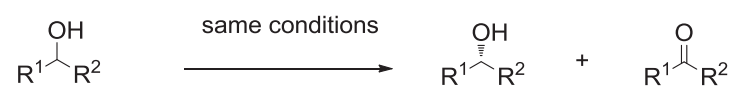

$53-56 \%$ conversion, $27-90 \%$ ee, $s=2.1-17.4$

$\mathrm{R}^{1}=n$-Pent, $t-\mathrm{Bu}, \mathrm{Me}, \mathrm{CH}_{2} \mathrm{Bn}, \mathrm{Ph}$

$\mathrm{R}^{2}=t$-Bu, 2-adamantyl, $\mathrm{Me}$

Scheme 18. Organocatalysed oxidative kinetic resolutions of cyclic and acyclic secondary aliphatic alcohols.

conversions (52-58\%) and good to excellent enantioselectivities (60-99\% ee) by using 2 or $5 \mathrm{~mol} \%$ of organocatalyst 15, TCCA as oxidant, $\mathrm{NaHCO}_{3}$ as additive in dichloromethane at $-40{ }^{\circ} \mathrm{C}$. The oxidative kinetic resolution of acyclic aliphatic alcohols was also achieved albeit with generally lower enantioselectivities (27-90\% ee) combined with good conversions (53-56\%), as shown in Scheme 18 (second equation). Moreover, synthetically useful cisand trans- $\alpha$-substituted heterocyclic alcohols $(X=0, N C b z, N B o c$, first equation) were compatible, providing low to remarkable enantioselectivities (3-99\% ee) in combination with good conversions (51-66\%). Selectivity factors of up to 297 were obtained for these latter reactions. It must be noted that this methodology represented the first successful example of resolving unactivated aliphatic secondary alcohols through organocatalysis having a wide substrate scope.

In 2014, Zhao et al. reported an enantioselective oxidative kinetic resolution of cis-1,2-diols catalysed with quinine-derived urea organocatalyst $16{ }^{48}$ This methodology using $N$-bromophthalimide as oxidant in chloroform as solvent at $24^{\circ} \mathrm{C}$ could be applied to the oxidative kinetic resolution of a cis-1,2-diol albeit with a low enantioselectivity (13\% ee) whereas the corresponding $\alpha$-hydroxyketone was obtained with $70 \%$ ee, as shown in Scheme 19.

Always the same year, Repo et al. demonstrated that $(R, R)-1,2$ -
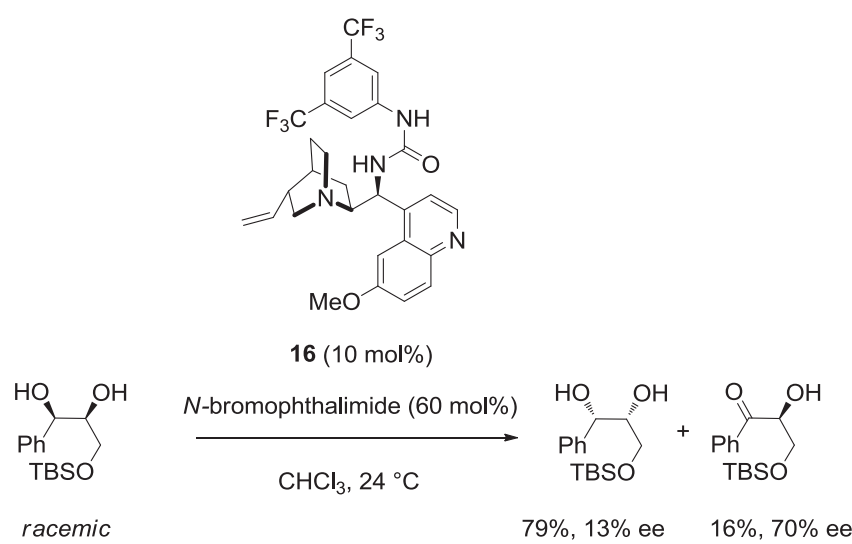

Scheme 19. Organocatalysed oxidative kinetic resolution of a cis-1,2-diol. 
di(1-naphthyl)-1,2-ethanediamine (NEDA) efficiently catalysed the oxidative kinetic resolution of secondary aromatic alcohols by using TBHP as oxidant. ${ }^{49}$ As shown in Scheme 20, the process was performed at room temperature in dichloromethane as solvent, which afforded the chiral alcohols with good conversions (39-52\%) and high enantioselectivities (83-98\% ee). Notably, even hindered cyclic carbinols, such as 1-tetranol and 1-indanol, were compatible, providing moderate to good enantioselectivities (67-82\% ee) along with good conversions (53-55\%).

The same year, a novel methodology for resolving secondary alcohols was reported by Kawabata et al. ${ }^{50}$ It was based on the use of $10 \mathrm{~mol} \%$ of chiral nitroxyl radical organocatalyst $\mathbf{1 7}$ in combination with phenyl iodonium bis(trifluoroacetate) (PIFA) as oxidant in the presence of $\mathrm{K}_{2} \mathrm{CO}_{3}$ as additive (Scheme 21). The reaction performed at $0{ }^{\circ} \mathrm{C}$ in dichloromethane led to a variety of aromatic and aliphatic secondary alcohols in good conversions (42-73\%), low to excellent enantioselectivities (2-99\% ee) and selectivity factors of 1-23. The highest enantioselectivities (94-99\% ee) were achieved in the oxidative kinetic resolution of tert-butyl benzylic alcohols while the lowest ones (2-7\% ee) were obtained when using 1phenylethanol and an allylic alcohol as substrates.

\section{Conclusions}

Along with epoxides, secondary alcohols have received the most attention in the context of catalytic kinetic resolution. In the last seven years, significant advances have been reported in the field of oxidative kinetic resolution of secondary racemic alcohols based on the use of various catalysts, including chiral manganese, palladium, vanadium, iridium and ruthenium complexes, and more environmentally benign and inexpensive iron chiral complexes, in addition to highly efficient organocatalysts more recently developed. Among these versatile procedures, many provided chiral alcohols with very high enantioselectivities and good conversions by using various types of chiral catalysts and green oxidants. For example, excellent results have been reported by employing chiral monomeric,

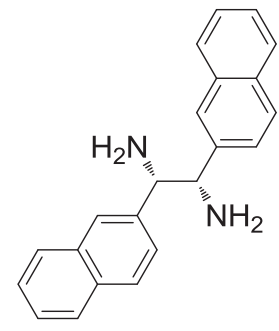

$(R, R)-N E D A(5 \mathrm{~mol} \%)$

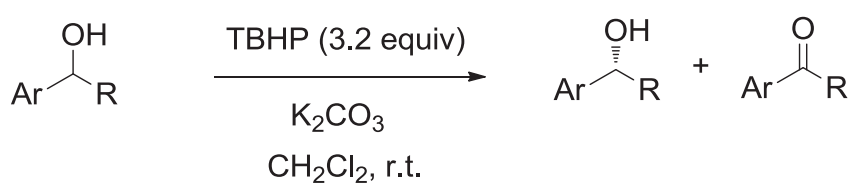

$39-52 \%$ conversion, $83-98 \%$ ee

$$
\begin{aligned}
& \mathrm{Ar}=\mathrm{Ph}, 2-\mathrm{Naph} \\
& \mathrm{R}=\mathrm{Me}, \mathrm{Et}
\end{aligned}
$$

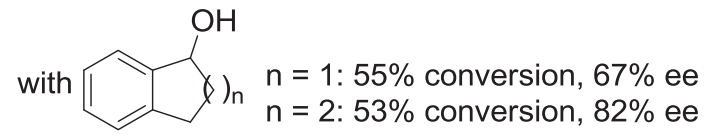

Scheme 20. Organocatalysed oxidative kinetic resolution of aromatic secondary alcohols.

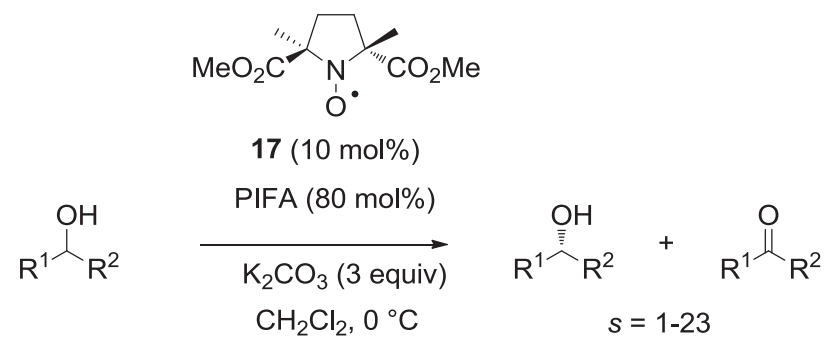

42-73\% conversion, $2-99 \%$ ee

$$
\begin{aligned}
& \mathrm{R}^{1}=\mathrm{Ph}, p-\mathrm{MeOC}{ }_{6} \mathrm{H}_{4}, p-\mathrm{CF}_{3} \mathrm{C}_{6} \mathrm{H}_{4}, 2-\mathrm{Naph}, 1-\mathrm{Naph},(E)-\mathrm{PhCH}=\mathrm{CH} \\
& \mathrm{R}^{2}=\mathrm{Me}, i-\mathrm{Pr}, t-\mathrm{Bu}
\end{aligned}
$$

Scheme 21. Oxidative kinetic resolution of secondary alcohols using a chiral nitroxyl radical organocatalyst.

dimeric, macrocyclic, polymeric and supported salen manganese complexes in the presence of $\mathrm{PhI}(\mathrm{OAc})_{2}$ as oxidant, or cheaper reagents such as NBS and NaClO. Furthermore, the use of environmentally benign $\mathrm{H}_{2} \mathrm{O}_{2}$ was recently reported in these reactions in combination with non-salen manganese complexes, such as tetradentate aminopyridine manganese catalysts. Excellent results were also achieved by using oxygen atmosphere in palladium-, vanadium- and ruthenium-catalysed oxidative kinetic resolutions of various secondary alcohols, and acetone as oxidant in iridiumcatalysed comparable reactions. Moreover, it is only in the last nine years that the first organocatalysed oxidative kinetic resolutions have been developed in the presence of different types of catalysts including ureas, diamines, chiral amine $\mathrm{N}$-oxyls, etc. combined to various types of oxidants, such as TCCA, acetone, $\mathrm{N}$ bromophthalimide, TBHP or PIFA. In the near future, the development of even more efficient chiral catalysts to promote green oxidative kinetic resolutions of various types of secondary alcohols, including unactivated and functionalised ones, is expected related to the importance of enantiomerically pure alcohols which are pivotal compounds in organic synthesis, present in many important target molecules, intermediates and reagents. In particular, the prospect of using oxygen from air as the direct and primary oxidant for these reactions makes it especially attractive from an environmental perspective.

\section{References}

1. (a) Kagan HB, Fiaud JC. Top Stereochem. 1988;18:249-330;

(b) Collins AN, Sheldrake GN, Crosby J. In: Chirality in Industry. Chichester: John Wiley and Sons; 1992;

(c) Koskinen A. In: Asymmetric Synthesis of Natural Products. New York: John Wiley and Sons Ltd; 1993;

(d) Nogradi M. In: Stereoselective Synthesis. Weinheim: Wiley-VCH; 1995;

(e) Atkinson SC. In: Stereoselective Synthesis. New York: Wiley and Sons; 1995;

(f) Gadamasetti KG. In: Process Chemistry in the Pharmaceutical Industry. New

York: Marcel Dekker; 1999;

(g) Blaser HU, Spindler F, Studer M. Appl Catal A. 2001;221:119-143;

(h) Noyori R. Adv Synth Catal. 2003;345:15-32;

(i) Blaser HU, Schmidt E. In: Asymmetric Catalysis on Industrial Scale, Challenges, Approaches and Solutions. Weinheim: Wiley-VCH; 2004;

(j) Farina V, Reeves JT, Senanayake CH, Song J. J Chem Rev. 2006;106: 2734-2793;

(k) Wu G, Huang M. Chem Rev. 2006;106:2596-2616.

2. (a) Hoveyda AH, Didiuk MT. Curr Org Chem. 1998;2:489-526;

(b) Cook GR. Curr Org Chem. 2000;4:869-885;

(c) Keith M, Larrow JF, Jacobsen EN. Adv Synth Catal. 2001;343:5-26;

(d) Robinson DEJE, Bull SD. Tetrahedron Asymmetry. 2003;14:1407-1446;

(e) Jarvo ER, Miller SJ. In: Jacobsen EN, Pfaltz A, Yamamoto H, eds. Comprehensive Asymmetric Catalysis, Supplement. Berlin: Springer; 2004:189-206;

(f) Breuer M, Ditrich K, Habicher T, et al. Angew Chem Int Ed. 2004;43:788-824; (g) Blaser HU, Schmidt E. In: Asymmetric Catalysis on Industrial Scale. Weinheim: Wiley-VCH; 2004;

(h) Vedejs E, Jure M. Angew Chem Int Ed. 2005;44:3974-4001;

(i) Fogassy E, Nogradi M, Kozma D, Egri G, Palovics E, Kiss V. Org Biomol Chem. 
2006;4:3011-3030;

(j) Wurz RP. Chem Rev. 2007;107:5570-5595

3. (a) Bredig G, Fajans K. Ber Dtsch Chem Ges. 1908;41:752-763;

(b) Fajans K. Phys Chem. 1910;73:25-96.

4. Martin VS, Woodard SS, Katsuki T, Yamada Y, Ikeda M, Sharpless KB. J Am Chem Soc. 1981;103:6237-6240.

5. (a) Sharpless KB, Verhoeven TR. Aldrichim Acta. 1979;12:63-74;

b) Finn MG, Sharpless KB. In: Morrison JD, ed. Asymmetric Synthesis. New York: Academic Press: 1985:247-308;

(c) Pfenninger A. Synthesis. 1986:89-116;

(d) Smith DB, Schreiber SL. Chemtracts. 1988;1:26-28;

(e) Reetz MT. Angew Chem Int Ed. 2001;40:284-310.

6. (a) Pellissier H. Adv Synth Catal. 2011;353:1613-1666;

(b) Pellissier H. In: Todd M, ed. Separation of Enantiomers, Synthetic Methods. Weinheim: Wiley-VCH; 2014;

(c) Petersen KS. Asian J Org Chem. 2016;5:308-320;

(d) Yang H, Zheng W-H. Tetrahedron Lett. 2018;59:583-591.

7. (a) Nicholas KM, Ferreira EM, Stoltz BM, Jensen DR, Pugsley JS, Sigman MS. Chemtracts. 2001;14:654-658;

(b). In: Jacobsen EN, Pfaltz A, Yamamoto H, eds. Comprehensive Asymmetric Catalysis, Suppl. 1. Heidelberg: Springer; 2004. chap. 43;

(c) Wills M. Angew Chem Int Ed. 2008;47:4264-4267.

8. Patel RN. Biomolecules. 2013:3:741-777.

9. Ahmad I, Shagufta, AlMallah AR. Chirality, 2017:29:798-810.

10. Petersen KS. Asian J Chem. 2016;5:308-320.

11. (a) Dehli JR, Gotor V. Chem Soc Rev. 2002;31:365-370;

b) Eames J. In: Schmalz HG, Wirth T, eds. Organic Synthesis Highlights V. Weinheim: Wiley-VCH; 2003:151-164.

12. (a) Nakamura S, Nakagawa R, Watanabe Y, Toru T. J Am Chem Soc. 2000;122: 11340-11347

(b) Sekar G, Nishiyama H. J Am Chem Soc. 2001;123:3603-3604;

(c) Bull SD, Davies SG, Garner AC, Mujtaba N. Synlett. 2001:781-784;

(d) Bailey S, Davies SG, Smith AD, Withey JM. Chem Commun. 2002:

2910-2911;

(e) Christoph G, Hoppe D. Org Lett. 2002;4:2189-2192.

13. (a) Noyori R, Tokunaga M, Kitamura M. Bull Chem Soc Jpn. 1995;68:36-56;

(b) Ward RS, Tetrahedron Asymmetry. 1995:6:1475-1490;

(c) Caddick S, Jenkins K. Chem Soc Rev. 1996:447-456;

(d) Stecher H, Faber K. Synthesis. 1997:1-16;

(e) El Gihani MT, Williams JMJ. Curr Opin Chem Biol. 1999;3:11-15

f) Azerad R, Buisson D. Curr Opin Chem Biol. 2000;11:565-571;

(g) Huerta FF, Minidis ABE, Bäckvall J-E. Chem Soc Rev. 2001:321-331;

(h) Kim MJ, Ahn Y, Park J. Curr Opin Biotechnol. 2002;13:578-587;

(i) Pellissier H. Tetrahedron. 2003;59:8291-8327;

(j) Pellissier H. Tetrahedron. 2008;64:1563-1601;

k) Pellissier H. Tetrahedron. 2011:67:3769-3802;

(1) Pellissier H. In: Chirality from Dynamic Kinetic Resolution. Cambridge: The Royal Society of Chemistry; 2011;

(m) Pellissier H. Adv Synth Catal. 2011;353:659-676;

(n) Pellissier H. Tetrahedron. 2016;72:3133-3150.

14. Sun W, Wang H, Xia C, Li J, Zhao P. Angew Chem Int Ed. 2003;42:1042-1044.

15. Pathak K, Ahmad I, Abdi SHR. J Mol Catal A. 2007:274:120-126.

16. (a) Kureshy RI, Ahmad I, Pathak K, et al. Chirality. 2007;19:352-357;

(b) Sun W, Wu X, Xia C. Helv Chim Acta. 2007;90:623-626.

17. (a) Kantam ML, Ramani T, Chakrapani L, Choudary BM. J Mol Catal A. 2007;274: $11-15$

(b) Sahoo S, Kumar P, Lefebvre F, Halligudi SB. Tetrahedron Lett. 2008;49: 4865-4868;

(c) Sahoo S, Kumar P, Lefebvre F, Halligudi SB. Appl Catal A. 2009;354:17-25.

18. Bera PK, Maity NC, Abdi SHR, Khan N-u H, Kureshy RI, Bajaj HC. Appl Catal A. 2013;467:542-551.

19. Li C, Zhao J, Tan R, et al. Catal Commun. 2011:15:27-31.

20. Tan R, Dong Y, Peng M, Zheng W, Yin D. Appl Catal A. 2013;458:1-10.

21. Tan C, Jiao J, Li Z, Liu Y, Han X, Cui YL. Angew Chem Int Ed. 2018;57:2085-2090.

22. Ren L, Li L, Li Y, et al. J Porous Mater. 2016;23:19-33.

23. Xu D, Wang S, Shen Z, Xia C, Sun W. Org Biomol Chem. 2012;10:2730-2732.

24. Zhang Y, Zhou Q, Ma W, Zhao J. Catal Commun. 2014;45:114-117.

25. Zhang Y, Gao B, Zhou Q, Zhao J. Catal Lett. 2014;144:1797-1802.

26. Maity NC, Kumar B, Prasanta SS, et al. ChemPlusChem. 2014;79:1426-1433.

27. Talsi EP, Samsonenko DG, Bryliakov KP. ChemCatChem. 2017:9:2599-2607.

28. Talsi EP, Bryliakov KP. ChemCatChem. 2018. https://doi.org/10.1002/ cctc. 201800180

29. Miao C, Li X-X, Lee Y-M, et al. Chem Sci. 2017;8:7476-7482.

30. (a) Ferreira EM, Stoltz BM. J Am Chem Soc. 2001;123:7725-7726;

(b) Jensen DR, Pugsley JS, Sigman MS. J Am Chem Soc. 2001;123:7475-7576;

(c) Mueller JA, Sigman MS. J Am Chem Soc. 2003;125:7005-7013;

(d) Jensen DR, Sigman MS. Org Lett. 2003;5:63-65;

(e) Mandal SK, Jensen DR, Pugsley JS, Sigman MS. J Org Chem. 2003;68: 4600-4603;

(f) Mandal SK, Sigman MS. J Org Chem. 2003;68:7535-7537;

(g) Bagdanoff JT, Ferreira EM, Stoltz BM. Org Lett. 2003;5:835-837;

(h) Jensen DR, Sigman MS. Org Lett. 2003;5:63-65;

(i) Trend RM, Stolz BM. J Am Chem Soc. 2004;126:4482-4483;

(j) Stoltz BM. Chem Lett. 2004;33:362-367; (k) Bagdanoff JT, Stoltz BM. Angew Chem Int Ed. 2004;43:353-357;

(1) Caspi DD, Ebner DC, Bagdanoff JT, Stoltz BM. Adv Synth Catal. 2004;346: 185-189;

(m) Mueller JA, Cowell A, Chandler BD, Sigman MS. J Am Chem Soc. 2005;127: 14817-14824;

(n) Thakur VV, Sudalai A. Indian J Chem B. 2005;44B:557-562;

(o) Sigman MS, Jensen DR. Acc Chem Res. 2006;39:221-229;

p) Tambar UK, Ebner DC, Stoltz BM. J Am Chem Soc. 2006;128:11752-11753;

(q) Ebner DC, Novak Z, Stoltz BM. Synlett. 2006;20:3533-3539;

(r) Trend RM, Stoltz BM. J Am Chem Soc. 2008;130:15957-15966;

(s) Ebner DC, Trend RM, Genet C, McGrath MJ, O'Brien P, Stoltz BM. Angew Chem Int Ed. 2008;47:6367-6370;

(t) Krishnan S, Bagdanoff JT, Ebner DC, Ramtohul YK, Tambar UK, Stoltz BM. J Am Chem Soc. 2008;130:13745-13754;

(u) Ebner DC, Bagdanoff JT, Ferreira EM, et al. Chem Eur J. 2009;15: 12978-12992.

31. (a) Dearden MJ, McGrath MJ, O'Brien PJ. Org Chem. 2004;69:5789-5792;

(b) Chen T, Jiang J-J, Xu Q, Shi M. Org Lett. 2007;9:865-868;

(c) O'Brien P. Chem Commun. 2008:655-667;

(d) Lesma G, Pilati T, Sacchetti A, Silvani A. Tetrahedron Asymmetry. 2008;19: 1363-1366;

(e) Breuning M, Steiner M, Mehler C, Paasche A, Hein D. J Org Chem. 2009;74: 1407-1410;

(f) Liu L j, Wang F, Shi M. Organometallics. 2009;28:4416-4420;

(g) Liu S-J, Liu L-j, Shi M. Appl Organomet Chem. 2009;23:183-190.

32. Meyer ME, Phillips JH, Ferreira EM, Stoltz BM. Tetrahedron. 2013;69: 7627-7635.

33. Hao B, Gunaratna MJ, Zhang M, et al. J Am Chem Soc. 2016:138:16839-16848.

34. (a) Radosevich AT, Misich C, Toste FD. J Am Chem Soc. 2005:127:1090-1091:

(b) Blanc A, Toste FD. Angew Chem Int Ed. 2006;45:2096-2099;

(c) Weng S-S, Shen M-W, Kao J-Q, Munot YS, Chen C-T. Proc Natl Acad Sci USA 2006;103:3522-3527;

(d) Pawar VD, Bettigeri S, Weng S-S, Kao J-O, Chen C-T. I Am Chem Soc. 2006:128:6308-6309;

(e) Chen C-T, Bettigeri S, Weng S-S, et al. J Org Chem. 2007;72:8175-8185;

(f) Radosevich AT, Chan VS, Shih H-W, Toste FD. Angew Chem Int Ed. 2008;47: 3755-3758;

(g) Yin L, Jia X, Li XS, Chan ASC. Chin Chem Lett. 2010;21:774-777.

35. Salunke SB, Babu NS, Chen C-T. Adv Synth Catal. 2011;353:1234-1240.

36. (a) Tan DM, Chan KS. Tetrahedron Lett. 2005;46:503-505;

(b) Nakamura Y, Egami H, Matsumoto K, Uchida T, Katsuki T. Tetrahedron. 2007:63:6383-6387.

37. Mizoguchi H, Uchida T, Katsuki T. Angew Chem Int Ed. 2014;53:3178-3182.

38. Muthupandi P, Alamsetti SK, Sekar G. Chem Commun. 2009:3288-3290.

39. Kunisu T, Oguma T, Katsuki T. J Am Chem Soc. 2011;133:12937-12939.

40. (a) Li YY, Zhang X-Q, Dong Z-R, Shen W-Y, Chen G, Gao J-X. Org Lett. 2006;8: 5565-5567;

(b) Arita S, Koike T, Kayaki Y, Ikariya T. Angew Chem Int Ed. 2008;47: 2447-2449;

(c) Ikariya T, Kuwata S, Kayaki Y. Pure Appl Chem. 2010;82:1471-1483.

41. Zhang J, Yang X, Zhou H, Li Y, Dong Z, Gao J. Green Chem. 2012;14:1289-1292.

42. Yamada T, Higano S, Yano T, Yamashita Y. Chem Lett. 2009;38:40-41.

43. (a) Onomura O, Arimoto H, Matsumura Y, Demizu Y. Tetrahedron Lett. 2007;48: 8668-8672;

(b) Alamsetti SK, Mannam S, Mutupandi P, Sekar G. Chem Eur J. 2009;15: 1086-1090;

(c) Mannam S, Sekar G. Tetrahedron Asymmetry. 2009;20:497-502.

44. Shi L, Wang Y, Li B, Wu L. Dalton Trans. 2014;43:9177-9188.

45. (a) Tomizawa M, Shibuya M, Iwabuchi Y. Org Lett. 2009;11:1829-1831;

(b) Tomizawa M, Shibuya M, Iwabuchi Y. Org Lett. 2014;16, 4968-4968.

46. Luo S, Zhou P, Li J, Cheng J-P. Chem Eur J. 2010;16:4457-4461.

47. Murakami K, Sasano Y, Tomizawa M, Shibuya M, Kwon E, Iwabuchi Y. J Am Chem Soc. 2014;136:17591-17600.

48. Rong Z-Q, Pan H-J, Yan H-L, Zhao Y. Org Lett. 2014;16:208-211.

49. Al-Hunaiti A, Räisänen M, Pihko P, Leskelä M, Repo T. Eur J Org Chem. 2014 6141-6144.

50. Hamada S, Wada Y, Sasamori T, Tokitoh N, Furura T, Kawabata T. Tetrahedron Lett. 2014;55:1943-1945.

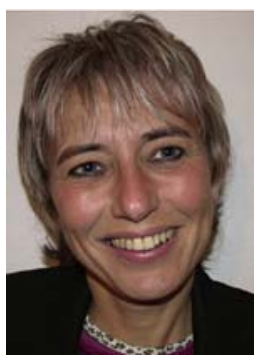

Hélène Pellissier carried out her PhD under the supervision of Dr G. Gil in Marseille (France) in 1987. The work was focused on the reactivity of isocyanides. In 1988, she entered the Centre National de la Recherche Scientifique postdoctoral period in Professor K. P. C. Vollhardt's group at the University of California, Berkeley, she joined the group of Professor M. Santelli in Marseille in 1992, where she focused on the chemistry of 1,8-bis(trimethylsilyl)-2,6-octadiene and its application to the development of novel very short total syntheses of steroids starting from 1,3-butadiene and benzocyclobutenes. She is currently chargée de recherche (CNRS) at Aix-Marseille Université. 